\title{
Exploring Differences between Faculty and Student Perceptions of Pre-clinical Preparation Activities
}

\author{
Laureen Turner*, Courtney Keeler, Daniel Long, Vernon Newton \\ School of Nursing and Health Professions, University of San Francisco, USA
}

Copyright $\subset 2017$ by authors, all rights reserved. Authors agree that this article remains permanently open access under the terms of the Creative Commons Attribution License 4.0 International License

\begin{abstract}
Introduction: A review of the literature demonstrates a paucity of research relating to faculty and student experiences regarding prelab. Given the increasing number of students entering nursing programs and the finite number of clinical sites, educators must weigh the relative benefits of each component of the clinical experience, including pre-laboratory (or "prelab") activities. Methods: The research team designed and administered a descriptive study exploring prelab practices and attitudes in one pre-licensure baccalaureate program among students and instructors. Mean comparison tests were used to assess differences in perceptions across the two groups. Results: The results emphasized a disconnection between student and faculty views on several critical indictors, including the impact of prelab on stress, anxiety, and sleep. Conclusion: While stress and anxiety are natural components to any learning process, students may gain more from prelab if stress or anxiety were reduced.
\end{abstract}

Keywords Nursing Education, Clinical Education, Pre-licensure, Preparation, Prelab

\section{Introduction}

As Auerbach and colleagues write [1], "The importance of RNs is expected to increase in the coming decades, as new models of care delivery, global payment, and a greater emphasis on prevention are embraced." The Institute of Medicine [2] has partially driven these changes, calling for radical, pedagogical-based transformations in nursing education. Additional market factors are also forcing changes in nursing education. On the demand side, the passage of the Patient Protection and Affordable Care Act may have led to an increase in the demand for nurses [1]. Moreover, with an aging population in the United States (US), the US will see increasing demands for care [3]. On the supply side, the nursing labor market is experiencing the counter effects of a wave of new nursing graduates and the pending retirement of an aging nursing workforce. Recent work suggests that the delayed retirement of registered nurses has actually led to an increase in the size of the nursing workforce [4].

With all these considerations in mind, the American Association of Colleges of Nursing (AACN) has cited the need to educate 1.05 million new nurses by 2022 [5]. To meet this demand, enrollment has increased in nursing schools across the country. While the increase in the number of nursing students is largely positive, the augmented student population does present new challenges, particularly when it comes to student placement in a finite number of clinical sites [6, 7]. As a result, educators must weigh the relative benefits of each component of the clinical experience, including pre-laboratory (or "prelab") activities as these activities are time consuming for both student and educator and additionally, utilize the finite clinical site for activities that are not directly related to patient care.

Typical nursing education includes both didactic content and clinical practice hours. These practice hours are thought to solidify the didactic learning and allow the student to practice bedside nursing care. However, little is known about the methods of preparing the student for the clinical day. This paper explores a very small piece of clinical education, prelab.

Prelab includes activities associated with preparing the student for his/her clinical experience, including patient selection, patient data collection, student research on the pathophysiology, medications, and treatments such that he/she can prepare a plan of care $[7,8,9]$. Prelab seeks to supplement the didactic course work, helping connect theory and clinical practice. Literature has suggested that prelab improves the student's ability to collect relevant data $[7,10$, 11, 12], enhances critical thinking [7, 13], strengthens research skills, and promotes self-directed learning [14] Prelab may help students develop a comprehensive plan of care, $[7,9,11]$, anticipate priority nursing diagnoses $[10,11$, 12], identify relevant nursing interventions [10], and implement nursing care plans [10, 11, 12].

Detractors argue that prelab shelters students from the 
time constraints associated with "real life" nursing practice. The prelab process itself can be highly time-consuming, by some estimates averaging students $5+$ hours $[7,10]$. Such a time consuming process may increase student anxiety and influence the student's ability to have an adequate amount of sleep before the clinical day [7]. Stress and sleep-deprivation have long-term implications for learning as well as patient safety.

This descriptive study investigated differences in student and faculty perceptions of prelab in one pre-licensure baccalaureate program in California. The results emphasized a disconnection between student and faculty views on several critical indicators, including the impact of prelab on stress, anxiety, and sleep.

\section{Methods}

\section{Design}

The research team designed and administered a descriptive study exploring prelab practices and attitudes in one pre-licensure baccalaureate program in California. Separate surveys were designed for students and instructors. Surveys were given to faculty and students during the same period (spring 2013). The study drew on a convenience sample of faculty and students who returned the survey. In total, 298 baccalaureate students returned the student survey (55\% response rate); 34 clinical BSN faculties completed the faculty survey ( $43 \%$ response rate). For the most part, the current analysis focused on the results from the faculty component.

\section{Instrument}

Drawing on drawing on existing instruments which have been validated within this population $[10,11,12,15]$, the research team developed two surveys: one for faculty and one for students. Surveys were distributed to seasoned nursing faculty serving as chairs or in other leading positions at each of the nursing programmatic levels in the School of Nursing. Experts' comments were incorporated and the survey updated according. The final versions of both surveys were returned to the quantitative expert and faculty leads for final approval. Surveys were not distributed until chairs/leads approved the survey. Content experts reviewed the faculty and student instruments and the surveys were revised based on their suggestions. The student and faculty survey consisted of several, basic demographic questions, five questions relating to the process of prelab, and $16-17$ Likert-style questions asking respondents to select one of several ranked responses. Cronbach's alpha estimates the reliability of a psychometric test.The internal reliability of both instruments was high (Cronbach's $\alpha$ of 0.80 and 0.81 for faculty and students, respectively).

While separate surveys were designed for students and instructors, the two surveys were designed to have corresponding questions. As a result, one can compare attitudes towards prelab across faculty and students. For instance, the student survey asked respondents how often they felt the following statement was accurate: "On the day of clinical, I provide safe care"; the corresponding question on the faculty survey asked, "On the day of clinical, students provide safe care." Both students and faculty were given the following options in responding: 1 (never), 2 (rarely), 3 (sometimes/occasionally), and 4 (very often). The analysis presented in the result section was passed on these data.

\section{Procedure}

The survey was emailed to all pre-licensure instructors who taught at least one clinical section in the baccalaureate program during the semester when the survey was administered $(\mathrm{N}=54) ; 63 \%$ of respondents returned the survey $(\mathrm{n}=34)$. The sample size is necessarily small, given the fixed number of faculty teaching in any given university. Similarly, the student survey was emailed to all students enrolled in clinical sections of courses $(\mathrm{N}=541) ; 298$ students returned completed surveys for a $55 \%$ response rate. Surveys were completed anonymously, protecting the identity of respondents. Given the small sample size, only a limited demographic data were collected from faculty, specifically data on race/ethnicity and gender. We decided not to report data on race/ethnicity in order to protect the privacy of the respondents. As such, specific responses cannot be traced to individual faculty or students. Data were stored on a password-protected computer and were only available to the research team. Both the instruments and the implementation process received approval from the school Institutional Review Board (IRB).

\section{Data Analysis}

The data were analyzed using Stata 14 (StataCorp, College Station, Texas). We ran a series of mean comparison tests to identify differences in perceptions of prelab between faculty and students. Welch's formula was used to calculate degrees of freedom. Mean differences were considered marginally significant, significantly, or highly significant if $p \leq 0.10, p \leq$ 0.05 , or $\mathrm{p} \leq 0.01$, respectively. Marginally significant, significant, or highly significant differences are indicated in all tables.

\section{Results}

\section{Instructor Characteristics}

The faculty sample consisted of pre-licensure instructors who taught at least one clinical section in the baccalaureate program during the semester when the survey was administered. The sample of clinical instructors comprised both full-time $(20.6 \%, n=7)$ and part-time $(79.4 \%, n=27)$ faculty. A majority of respondents reported his/her highest level of educational attainment as either a Bachelor of 
Science in Nursing (BSN) $(38.2 \%, \mathrm{n}=13)$ or a Master of Science in Nursing (MSN) $(44.1 \%, n=15)$. A minority of respondents indicated that they have worked in nursing for less than five years $(14.7 \%, \mathrm{n}=5)$. Considering years in nursing education, $63.6 \%(\mathrm{n}=21)$ of respondents reported teaching for fewer than five years. Given the small sample size, only a limited demographic data were collected from faculty, although, of note, a majority of the faculty samples were female.

\section{Student Characteristics}

A majority were female (84\%), averaging 23 years of age. Students were relatively evenly distributed across grade-level, including sophomores $(\mathrm{n}=98)$, juniors $(\mathrm{n}=128)$, and seniors $(\mathrm{n}=70)$. Approximately, $44 \%$ of the samples were freshman entry (non-transfer) students. A majority $(63 \%)$ of clinical sections engaged in some form of prelab. Students described patient's assignment as follows: "student selected" ( $\mathrm{n}=118,44.4 \%)$, "unit staff assigned" ( $\mathrm{n}=106$, $39.8 \%)$, or "instructor assigned" $(\mathrm{n}=40,15 \%)$. A majority of students reported that they completed prelab the day before clinical $(n=222,89.5 \%)$. Faculty and students alike reported that the time spent on prelab was significant. Indeed, a majority of students reported spending more than an hour completing both onsite $(63.7 \% \mathrm{n}=200)$ and offsite $(86.6 \%$ $\mathrm{n}=272$ ) activities.

\section{Differences in Perceptions of Prelab across Faculty and Students}

Table 1 presents mean results across several dimensions for the student $(\mathrm{n}=298)$ and faculty $(\mathrm{n}=34)$ samples. The results suggest several key differences. Compared to faculty, students are more likely to report that Prelab hinders their ability to sleep $(2.45$ vs. $3.21 ; \mathrm{p}<0.01)$ and increases anxiety ( 3.25 vs. $3.89 ; \mathrm{p}<0.01)$. Relative to students, the faculty feels more strongly that Prelab enhances critical thinking (3.62 vs. $3.89 ; \mathrm{p}<0.05)$, informatics skills ( 3.27 vs. $3.63 ; \mathrm{p}<0.10)$, and the collection of relevant patient information (3.73 vs. 4.11 ; $\mathrm{p}<0.05)$. Faculty and students also differed in their opinions of the role of stress in the Prelab process; these distinctions are discussed in detail later in this section.

\section{The Impact of Stress on the Perceived Benefits of Prelab, Differences between Faculty and Students}

The results from the student survey indicated that a majority of students agreed or strongly agreed that Prelab increases stress $(\mathrm{n}=198,71 \%)$. Only $21.4 \%(\mathrm{n}=6)$ of faculty rated student stress level as high or very high on the day of Prelab. Table 2 presents the results of the survey stratified by perceived stress level. No significant differences were identified across all parameters explored. The findings counter previously published findings (10) relating to students. Specifically, the results from the student survey not only highlighted the high level of student stress surrounding Prelab, but also emphasized how student stress diminished the potential benefits gained from the Prelab experience. Nevertheless, faculty perceptions of Prelab do not appear to be impacted by perceived student stress levels. This major incongruity warrants further investigation.

\section{Differences in Perceptions of Prelab between Instructors across Teaching Status (Part-Time Vs. Full-Time Faculty)}

In our sample, $79.4 \%$ of respondents $(\mathrm{n}=27)$ identified as part-time and $20.6 \%(n=7)$ identified as full-time. Table 3 presents the results of the survey stratified by teaching status. We disaggregated the data into two distinct groups: part- and full-time faculty. While there are some differences, generally part-time and full-time faculties hold similar views on the value of Prelab. The only significant difference indicated in our results relates to faculty's opinion on whether students are able to "provide safe care" on the day of Prelab. Specifically, the part-time faculty felt less confident in the ability of their students to provide safe care relative to their full-time counterparts ( 3.81 vs. $4.00 ; \mathrm{p}<0.05$ ). Although this is the only significant distinction, it is crucial.

\section{Differences in Perceptions of Prelab between Instructors across Years Working in Nursing (Worked in Nursing for 5 or More Years vs. Worked in Nursing for Less Than 5 Years)}

In our sample, $85.3 \%$ of individuals $(\mathrm{n}=29)$ reported working in nursing for 5 or more years; $14.7 \%(n=5)$ reported working in nursing for less than 5 years. Table 4 presents the results of the survey stratified by years working in nursing. There are two important distinctions worth noting. Instructors who worked in nursing for 5 or more years felt less strongly that Prelab improved student's ability to complete clinical paperwork $(3.55$ vs. $4.20 ; \mathrm{p}<0.01)$ or enhanced the quality of their written work (3.50 vs. 4.40 ; $\mathrm{p}<0.05)$.

\section{Differences in Perceptions of Prelab across Years Teaching Nursing (Taught for 5 or More Years vs. Taught for Less Than 5 Years)}

$36.4 \%(\mathrm{n}=12)$ of respondents reported teaching for at least 5 years; $63.6 \%(\mathrm{n}=21)$ of respondents reported teaching for less than 5 years. Table 5 presents the results of the survey stratified by years teaching. The results emphasize continuity of opinion. The only area of disagreement related to post-conference discussion. Specifically, newer teachers were less likely to feel that Prelab improves the quality of post-conference discussion ( 2.88 vs. $3.91 ; \mathrm{p}<0.05)$. 
Table 1. Mean Comparison t Test for Select Outcomes Across Faculty and Students a,b

\begin{tabular}{|c|c|c|c|c|c|}
\hline \multirow{2}{*}{ How often are these statements accurate? ${ }^{c}$} & \multicolumn{2}{|c|}{ Student } & \multicolumn{2}{|c|}{ Faculty } & \multirow[t]{2}{*}{ t-stat } \\
\hline & & & & & \\
\hline (Students are/I am) prepared to care for their patients & 3.44 & $(0.55)$ & 3.50 & $(0.58)$ & 0.49 \\
\hline (Students/I) get good night's rest the night before clinical & 2.45 & $(0.91)$ & 3.21 & $(0.50)$ & $7.00^{\mathrm{g}}$ \\
\hline (Students/I) provide safe care & 3.85 & $(0.35)$ & 3.86 & $(0.36)$ & 0.05 \\
\hline \multicolumn{6}{|l|}{ How much do you agree with the following statements? ${ }^{d}$} \\
\hline Prelab enhances student safety & 3.56 & $(0.91)$ & 4.04 & $(1.04)$ & $2.32^{\mathrm{f}}$ \\
\hline Prelab enhances students' critical thinking during clinical & 3.62 & $(0.98)$ & 3.89 & $(1.05)$ & 1.29 \\
\hline Students who Prelab complete more thorough paperwork & 3.41 & $(1.03)$ & 3.74 & $(1.02)$ & 1.61 \\
\hline Students who Prelab develop enhanced informatics skills & 3.27 & $(1.05)$ & 3.63 & $(0.97)$ & $1.84^{\mathrm{e}}$ \\
\hline Prelab increases student anxiety in the clinical setting & 3.25 & $(1.01)$ & 3.89 & $(1.03)$ & $3.11^{\mathrm{g}}$ \\
\hline Prelab helps students identify and collect relevant patient information & 3.73 & $(0.95)$ & 4.11 & $(0.83)$ & $2.27^{\mathrm{f}}$ \\
\hline Prelab helps students develop and implement the nursing care plan & 3.50 & $(1.00)$ & 3.82 & $(0.96)$ & 1.62 \\
\hline Prelab increases student familiarity with equipment & 2.63 & $(0.87)$ & 2.70 & $(1.17)$ & 0.30 \\
\hline Prelab enhances student acquisition of psychomotor skills & 2.80 & $(0.93)$ & 3.00 & $(1.06)$ & 0.93 \\
\hline Prelab improves the quality of post conference discussion & 3.65 & $(1.00)$ & 3.30 & $(1.20)$ & -1.48 \\
\hline
\end{tabular}

a. Wording of some questions slightly different depending on whether question asked of students or faculty.

b. Degrees of freedom for mean comparison test from Welch's formula.

c. Responses range from 1 (never) to 4 (very often)

d. Responses range from 1 (strongly disagree) to 5 (strongly agree).

e. $\mathrm{p}<0.10$

f. $\mathrm{p}<0.05$

g. $\mathrm{p}<0.01$

Table 2. Mean Comparison $t$ Test for Outcomes by Perceived Student Stress Level ${ }^{\text {a }}$

\begin{tabular}{|c|c|c|c|c|c|}
\hline How often are these statements accurate? ${ }^{b}$ & \multicolumn{2}{|c|}{$\begin{array}{c}\text { Low or moderate perceived } \\
\text { stress }\end{array}$} & \multicolumn{2}{|c|}{$\begin{array}{l}\text { High or very high } \\
\text { perceived stress }\end{array}$} & t-stat \\
\hline Students are prepared to care for their patients & 3.59 & $(0.50)$ & 3.17 & $(0.75)$ & 1.30 \\
\hline Students get good night's rest the night before clinical & 3.23 & $(0.53)$ & 3.17 & $(0.41)$ & 0.30 \\
\hline Students provide safe care & 3.86 & $(0.35)$ & 3.83 & $(0.41)$ & 0.17 \\
\hline \multicolumn{6}{|l|}{ How much do you agree with the following statements? ${ }^{c}$} \\
\hline Prelab enhances student safety & 4.18 & $(0.91)$ & 3.50 & $(1.38)$ & 1.15 \\
\hline Prelab enhances students' critical thinking during clinical & 4.00 & $(0.95)$ & 3.50 & $(1.38)$ & 0.83 \\
\hline Students who Prelab complete more thorough paperwork & 3.76 & $(1.00)$ & 3.67 & $(1.21)$ & 0.18 \\
\hline Students who Prelab develop enhanced informatics skills & 3.62 & $(0.92)$ & 3.67 & $(1.21)$ & -0.09 \\
\hline Prelab increases student anxiety in the clinical setting & 3.91 & $(0.97)$ & 3.83 & $(1.33)$ & 0.13 \\
\hline Prelab helps students identify and collect relevant patient information & 4.14 & $(0.71)$ & 4.00 & $(1.27)$ & 0.25 \\
\hline Prelab helps students develop and implement the nursing care plan & 3.86 & $(0.91)$ & 3.67 & $(1.21)$ & 0.36 \\
\hline Prelab increases student familiarity with equipment & 2.71 & $(1.15)$ & 2.67 & $(1.37)$ & 0.08 \\
\hline Prelab enhances student acquisition of psychomotor skills & 2.90 & $(1.07)$ & 3.33 & $(1.03)$ & -0.89 \\
\hline Prelab improves the quality of post conference discussion & 3.52 & $(1.08)$ & 2.50 & $(1.38)$ & 1.68 \\
\hline Prelab improves the quality of students written work & 3.76 & $(0.89)$ & 3.33 & $(1.21)$ & 0.81 \\
\hline Prelab increases student stress level & 2.81 & $(1.03)$ & 3.33 & $(1.51)$ & -0.80 \\
\hline Prelab decreases the students ability to get a full night's sleep & 3.10 & $(1.04)$ & 3.50 & $(1.38)$ & -0.67 \\
\hline
\end{tabular}

a. Degrees of freedom for mean comparison test from Welch's formula.

b. Responses range from 1 (never) to 4 (very often)

c. Responses range from 1 (strongly disagree) to 5 (strongly agree). 
Table 3. Mean Comparison $t$ Test for Outcomes by Teaching Status ${ }^{a}$

\begin{tabular}{|c|c|c|c|c|c|}
\hline \multirow[b]{2}{*}{ How often are these statements accurate? ${ }^{b}$} & \multicolumn{2}{|c|}{ Part-time } & \multicolumn{2}{|c|}{ Full-time } & \multirow[t]{2}{*}{ t-stat } \\
\hline & & & & & \\
\hline Students are prepared to care for their patients & 3.43 & $(0.60)$ & 3.71 & $(0.49)$ & -1.27 \\
\hline Students get good night's rest the night before clinical & 3.14 & $(0.48)$ & 3.43 & $(0.54)$ & -1.26 \\
\hline Students provide safe care & 3.81 & $(0.40)$ & 4.00 & $(0.00)$ & $-2.17^{\mathrm{d}}$ \\
\hline \multicolumn{6}{|l|}{ How much do you agree with the following statements? ${ }^{c}$} \\
\hline Prelab enhances student safety & 4.14 & $(0.96)$ & 3.71 & $(1.25)$ & 0.83 \\
\hline Prelab enhances students' critical thinking during clinical & 3.95 & $(1.05)$ & 3.71 & $(1.11)$ & 0.49 \\
\hline Students who Prelab complete more thorough paperwork & 3.90 & $(0.91)$ & 3.29 & $(1.25)$ & 1.19 \\
\hline Students who Prelab develop enhanced informatics skills & 3.75 & $(0.85)$ & 3.29 & $(1.25)$ & 0.91 \\
\hline Prelab increases student anxiety in the clinical setting & 4.10 & $(0.94)$ & 3.29 & $(1.11)$ & 1.73 \\
\hline Prelab helps students identify and collect relevant patient information & 4.24 & $(0.70)$ & 3.71 & $(1.11)$ & 1.17 \\
\hline Prelab helps students develop and implement the nursing care plan & 3.95 & $(0.89)$ & 3.43 & $(1.13)$ & 1.10 \\
\hline Prelab increases student familiarity with equipment & 2.55 & $(1.10)$ & 3.14 & $(1.35)$ & -1.05 \\
\hline Prelab enhances student acquisition of psychomotor skills & 2.95 & $(0.97)$ & 3.14 & $(1.35)$ & -0.35 \\
\hline Prelab improves the quality of post conference discussion & 3.25 & $(1.21)$ & 3.43 & $(1.27)$ & -0.32 \\
\hline Prelab improves the quality of students written work & 3.80 & $(0.83)$ & 3.29 & $(1.25)$ & 1.01 \\
\hline Prelab increases student stress level & 2.80 & $(1.01)$ & 3.29 & $(1.50)$ & -0.80 \\
\hline Prelab decreases the students ability to get a full nights sleep & 3.20 & $(1.01)$ & 3.14 & $(1.46)$ & 0.10 \\
\hline
\end{tabular}

a. Degrees of freedom for mean comparison test from Welch's formula.

b. Responses range from 1 (never) to 4 (very often)

c. Responses range from 1 (strongly disagree) to 5 (strongly agree).

d. $\mathrm{p}<0.05$

Table 4. Mean Comparison $t$ Test for Outcomes by years working in nursing ${ }^{a}$

\begin{tabular}{|c|c|c|c|c|c|}
\hline \multirow[b]{2}{*}{ How often are these statements accurate? ${ }^{b}$} & \multicolumn{2}{|c|}{ Worked in nursing $\geq 5$ years, } & \multicolumn{2}{|c|}{ Worked in nursing $<5$ years } & \multirow[t]{2}{*}{ t-stat } \\
\hline & & & & & \\
\hline Students are prepared to care for their patients & 3.52 & $(0.59)$ & 3.40 & $(0.55)$ & 0.44 \\
\hline Students get good night's rest the night before clinical & 3.22 & $(0.52)$ & 3.20 & $(0.45)$ & 0.08 \\
\hline Students provide safe care & 3.91 & $(0.29)$ & 3.60 & $(0.55)$ & 1.24 \\
\hline \multicolumn{6}{|l|}{ How much do you agree with the following statements? ${ }^{c}$} \\
\hline Prelab enhances student safety & 4.04 & $(1.02)$ & 4.00 & $(1.23)$ & 0.07 \\
\hline Prelab enhances students' critical thinking during clinical & 3.86 & $(1.04)$ & 4.00 & $(1.23)$ & -0.23 \\
\hline Students who Prelab complete more thorough paperwork & 3.55 & $(1.01)$ & 4.60 & $(0.55)$ & $-3.23^{\mathrm{e}}$ \\
\hline Students who Prelab develop enhanced informatics skills & 3.50 & $(0.96)$ & 4.20 & $(0.84)$ & -1.64 \\
\hline Prelab increases student anxiety in the clinical setting & 3.83 & $(1.07)$ & 4.20 & $(0.84)$ & -0.86 \\
\hline Prelab helps students identify and collect relevant patient information & 4.04 & $(0.88)$ & 4.40 & $(0.55)$ & -1.17 \\
\hline Prelab helps students develop and implement the nursing care plan & 3.77 & $(0.97)$ & 4.00 & $(1.00)$ & -0.46 \\
\hline Prelab increases student familiarity with equipment & 2.73 & $(1.12)$ & 2.60 & $(1.52)$ & 0.18 \\
\hline Prelab enhances student acquisition of psychomotor skills & 2.86 & $(1.06)$ & 3.60 & $(0.89)$ & -1.61 \\
\hline Prelab improves the quality of post conference discussion & 3.32 & $(1.13)$ & 3.20 & $(1.64)$ & 0.15 \\
\hline Prelab improves the quality of students written work & 3.50 & $(0.96)$ & 4.40 & $(0.55)$ & $-2.82^{d}$ \\
\hline Prelab increases student stress level & 2.96 & $(1.05)$ & 2.80 & $(1.64)$ & 0.20 \\
\hline Prelab decreases the students ability to get a full night's sleep & 3.32 & $(0.89)$ & 2.60 & $(1.82)$ & 0.86 \\
\hline
\end{tabular}

a. Degrees of freedom for mean comparison test from Welch's formula.

b. Responses range from 1 (never) to 4 (very often)

c. Responses range from 1 (strongly disagree) to 5 (strongly agree).

d. $\mathrm{p}<0.05$

e. $\mathrm{p}<0.01$ 
Table 5. Mean Comparison t Test for Outcomes by Years in Teaching ${ }^{a}$

\begin{tabular}{|c|c|c|c|c|c|}
\hline \multirow[b]{2}{*}{ How often are these statements accurate? ${ }^{b}$} & \multicolumn{2}{|c|}{ Nursing instructor $\geq 5$ years } & \multicolumn{2}{|c|}{ Nursing instructor $<5$ years } & \multirow[t]{2}{*}{ t-stat } \\
\hline & & & & & \\
\hline Students are prepared to care for their patients & 3.55 & $(0.52)$ & 3.47 & $(0.62)$ & 0.34 \\
\hline Students get good night's rest the night before clinical & 3.27 & $(0.65)$ & 3.18 & $(0.39)$ & 0.44 \\
\hline Students provide safe care & 3.91 & $(0.30)$ & 3.82 & $(0.39)$ & 0.65 \\
\hline \multicolumn{6}{|l|}{ How much do you agree with the following statements? ${ }^{c}$} \\
\hline Prelab enhances student safety & 4.18 & $(0.87)$ & 3.94 & $(1.14)$ & 0.63 \\
\hline Prelab enhances my students' critical thinking during clinical & 4.10 & $(0.74)$ & 3.77 & $(1.20)$ & 0.90 \\
\hline Students who Prelab complete more thorough paperwork & 4.10 & $(0.99)$ & 3.53 & $(1.01)$ & 1.43 \\
\hline Students who Prelab develop enhanced informatics skills & 3.70 & $(0.95)$ & 3.59 & $(1.00)$ & 0.29 \\
\hline Prelab increases student anxiety in the clinical setting & 4.09 & $(0.94)$ & 3.77 & $(1.09)$ & 0.84 \\
\hline Prelab helps students identify and collect relevant patient information & 4.09 & $(0.83)$ & 4.12 & $(0.86)$ & -0.08 \\
\hline Prelab helps students develop and implement the nursing care plan & 4.00 & $(1.00)$ & 3.69 & $(0.95)$ & 0.82 \\
\hline Prelab increases student familiarity with equipment & 3.00 & $(1.18)$ & 2.50 & $(1.16)$ & 1.09 \\
\hline Prelab enhances student acquisition of psychomotor skills & 3.10 & $(1.10)$ & 2.94 & $(1.06)$ & 0.37 \\
\hline Prelab improves the quality of post conference discussion & 3.91 & $(1.04)$ & 2.88 & $(1.15)$ & $2.43^{\mathrm{d}}$ \\
\hline Prelab improves the quality of students written work & 3.82 & $(0.87)$ & 3.56 & $(1.03)$ & 0.69 \\
\hline Prelab increases student stress level & 3.00 & $(1.18)$ & 2.88 & $(1.15)$ & 0.27 \\
\hline $\begin{array}{l}\text { Prelab decreases the students ability to get a full night's sleep before } \\
\text { clinical }\end{array}$ & 3.36 & $(0.92)$ & 3.06 & $(1.24)$ & 0.72 \\
\hline
\end{tabular}

a. Degrees of freedom for mean comparison test from Welch's formula.

b. Responses range from 1 (never) to 4 (very often)

c. Responses range from 1 (strongly disagree) to 5 (strongly agree).

d. $\mathrm{p}<0.05$

\section{Discussion}

The findings highlighted a fundamental disconnect between perceived stress levels regarding prelab. Of equal or more importance, faculty and students had different views on the role of prelab in enhancing student safety - students felt less strongly that prelab increased safe practices, suggesting that faculty should consider interventions to bridge this divide.

There were several limitations to this work. First, the sample size was necessarily small, limiting the external validity of this study. That said, the sample provides a strong representation of faculty and student views at the surveyed institution and may be generalizable to similar learning environments. Second, we did not conduct a pretest. These data reflect a preliminary round of sampling, which we hope to compare to subsequent rounds of survey results at a later date. That said, we think the initial survey results are quite interesting and worthy of study in of themselves. Research based on the same data that focused solely on the student findings has been published elsewhere [7]. Third, with any survey, there are always challenges to internal validity. Namely, are you measuring what you think you are measuring? To address this issue, we drew on existing instruments previously validated within this population $[10$, 11, 12, 15]; moreover, surveys were developed in conjunction with and vetted by content experts. Further,
Cronbach's alpha estimates highlight the reliability results. Finally, the survey does not collect data on prelab alternatives. Defining and assessing perceptions about these alternatives could be helpful.

Despite these limitations, several key recommendations emerge from this work. While stress and anxiety are a natural component to any learning process, students may gain more from prelab if stress or anxiety could, in some way, be reduced. Faculty may not be aware of the length of time students spend completing prelab assignments or the stress associated with the assignments. Perhaps the benefits of prelab could be better optimized by altering the timing of assignments, augmenting the instructor guidance, better explaining the process, and creating less time consuming assignments could reap huge gains. At a more fundamental level, the gap in perception about the benefits of prelab could be potentially reduced if, all else equal, the faculty simply acknowledged to students that they understand that the process is stressful. Indeed, the literature demonstrates the positive effects of empathy in the classroom. For instance, Tevon and McCroskey found that perceived teacher caring was positively associated with not only student evaluations of instructors but also affective and cognitive learning [16].

Further interventions among clinical students in non-nursing fields also show promise. For example, in attempting to moderate stress-levels among first year medical students, Moffat and colleagues found that 
increasing avenues for student feedback, faculty guidance, and access to learning resources may decrease students stress levels [17]. So, indeed, in optimizing prelab success and mitigating student stress, the solution may revolve around faculty acknowledging the presence of student stress; and, in response highlighting the availability of resources and advising that, in all likelihood, already are well in place rather than modifying the prelab process itself.

Future research should try to identify trends in prelab practices at the national level. Prospective longitudinal and experimental studies comparing experiences of students who do and do not engage in prelab might further help clarify questions relating to the practice. Finally, many additional questions remain unanswered, including the optimal form of patient assignment, the ideal length of time a student should spend on prelab assignments, and an identification of a functional balance between the stress-rigor tradeoff.

\section{REFERENCES}

[1] Auerbach, D. I., Staiger, D. O., Muench, U., \& Buerhaus, P. I. (2013). The nursing workforce in an era of health care reform. New England Journal of Medicine, 368(16), 1470-1472.

[2] Institute of Medicine \& Robert Wood Johnson Foundation. (2010). The future of nursing: Focus on education. Washington DC: National Academic Press.

[3] Juraschek, S. P., Zhang, X., Ranganathan, V., \& Lin, V. W. (2012). United States registered nurse workforce report card and shortage forecast. American Journal of Medical Quality, 27(3), 241-249.

[4] Auerbach, D. I., Buerhaus, P. I., \& Staiger, D. O. (2014). Registered nurses are delaying retirement, a shift that has contributed to recent growth in the nurse workforce. Health Affairs, 33(8), 1474-1480.

[5] American Association of Colleges of Nursing. (2015). Nursing shortage fact sheet. Retrieved from http://www.aacn.nche.edu/media-relations/fact-sheets/nursin g-shortage
[6] Kline, K., \& Hodges, J., (2006). A rational approach to solving the problem of competition for undergraduate clinical sites. Nursing Education Perspectives, 27, 80-83.

[7] Turner, L., \& Keeler, C. (2015). Should we prelab? A student-centered look at the time-honored tradition of prelab in clinical nursing education. Nurse Educator, 40(2), 91-95. doi:10.1097/NNE.0000000000000095

[8] Benner, P. E. (1984). From novice to expert: Excellence and power in clinical nursing practice. Menlo Park, CA: Addison-Wesley Pub Co., Nursing Division.

[9] Ham, K., \& O'Rourke, E. (2004). Clinical preparation for beginning nursing students. Nurse Educator, 29(4), 139-141.

[10] McCoin, D., \& Jenkins, P. (1988). Methods of assignment for preplanning activities (advance student preparation) for the clinical experience. Journal of Nursing Education, 27, 85-87.

[11] Smith, B., \& Johnston, Y., (2002). Using structured clinical preparation to stimulated reflection and foster critical thinking. Journal of Nursing Education, 42, 182-185.

[12] Villafuerte, A. (1996). Structured clinical preparation time for culturally diverse baccalaureate nursing students. International Journal of Nursing Studies, 33(2), 161-170.

[13] Twibell, R., Ryan, M., \& Hermiz, M. (2005). Faculty perceptions of critical thinking in student clinical experiences. Journal of Nursing Education, 44(2), 71-79.

[14] Blomberg, K., Bisholt, B., Kullen Engstorm, A., Ohlsson, U., Sundler Johansson, A., \& Gustafsson, M. (2014). Swedish nursing students' experience of stress during clinical practice in relation to clinical setting characteristics and the organization of the clinical education. Journal of Clinical Nursing, 23, 2264-2271. Doi:10.1111/jocn.12506

[15] Hickey, M. T. (2010). Baccalaureate nursing graduates' perceptions of their clinical instructional experiences and preparation for practice. Journal of Professional Nursing 26(1), 35-41. http://doi.org/10.1016/j.profnurs.2009.03.001

[16] Teven, J. J., \&amp; McCroskey, J. C. (1997). The relationship of perceived teacher caring with student learning and teacher evaluation. Communication Education, 46(1), 1-9.

[17] Moffat, K. J., McConnachie, A., Ross, S., \&amp; Morrison, J. M. (2004). First year medical student stress and coping in a problem - based learning medical curriculum. Medical education, 38(5), 482-491. 